\title{
Ward sister - manager nurse, or teacher?
}

\author{
REPRINTED FROM NURSING MIRROR, 18 MAY 1978 BY COURTESY OF THE EDITOR AND \\ THE AUTHOR
}

This article is based on an essay by John Sheahan, SRN, RMN, RNT, Principal Lecturer in Nursing, The Polytechnic, Huddersfield, which won second place in the Baillière Prize for Nursing Studies, 1977.

$\mathbf{T}$ he title of this essay questions whether a ward sister is a manager, a nurse, or a teacher. Each of the three elements will be defined and discussed in turn in an attempt to answer the questions.

\section{Management}

What is management? The Concise Oxford Dictionary deals with the verb "to manage" as follows: this can vary in the meaning from "to handle, wield control, via to contrive" in the sense of "he managed to make a muddle", to succeed in one's aim or "to make proper use of". In the case of the word "management", the dictionary says that its meaning can range from the "art of handling", to the business of "deceitful contrivance".

A prerequisite for any kind of management is planning. Associated with planning are objectives. These objectives are long-term, short-term, general, and specific, and because to some they appear to be jargon terms, they are often left alone. If the word "intention" was substituted for objectives, it is likely that this would be more significant. It may be the intention of a sister on a surgical ward, for example, to reduce or eliminate postoperative infections. To achieve her objective she will have to make her intentions known to her staff. She will have to involve doctors and possibly other staff and she will need to modify and adjust existing practices.

The sister on a surgical ward is one example; sisters in paediatric, geriatric, psychiatric, and neurological wards, as well as those working in the community, will each have their own set of intentions appropriate to the setting and will have a plan.

Management, like nursing, is a process and the next element in the process is organising. In management terms, organisation is the division of activities and is concerned, for example, with who reports to whom. It is interesting that communication features in many of the Royal College of Nursing research reports. Lelean (1973) deals with the subject at some length. During a span of duty, $08.00 \mathrm{~h}$ to $12.00 \mathrm{~h}$, it was found that "the average duration of the sister's communication with nurses, doctors, and other personnel was 135 minutes, the range being 90 to 180 minutes". Later she goes on to say: "As many as 20 other hospital personnel could communicate with the sister during one morning. Other personnel initiated the communication more frequently than did sister. The duration of communication was usually less than one minute."

Anderson (1973) writes: "Patients should be given the opportunity to ask questions during routine nursing rounds. The importance of explaining procedures to patients must be stressed when teaching students."

Jones (1975) includes aspects of communication in his study of the feeding of unconscious patients. He found that the interpretation of instructions was a problem. When dealing with diet sheets, he says: "A record sheet should be devised which will enable junior nurses to see if the patient has received the recommended nutrients and fluids. Not only would this provide a simple measurement tool for nurses but it would also get over the difficulty of the interpretation of verbal prescriptions."

In another study Hayward (1975) found: "The major experimental hypothesis that giving information would reduce postoperative pain and anxiety was upheld for total samples from each hospital, and for one of the two sub-groups from the second hospital. This finding supports the contention that "informed" talking is more effective in this context than "just talking". The author goes on to suggest that the old teaching adage may provide a practical guide in giving information to patients.

1. Tell 'em what you're going to tell 'em.

2. Tell 'em

3. Tell 'em what you've told 'em.

Directing comes after organising in the management process. The Concise Oxford Dictionary defines direct as "going straight as possible to the point." This succinct definition assumes at least two important conditions: first, that the point is known, and second, that these intentions are communicated clearly to the people involved.

It is now proposed to examine a state of affairs in a general hospital ward with a view to considering the management involved. A man who is about to be discharged collapses and dies suddenly from a coronary thrombosis. During his stay in hospital the sister got to know this person well. She knows about his pesition as a husband, a father of a young family, a breadwinner, and a person on whom many have relied. 
The sister now has the job of breaking the news to the distraught wife and relatives and conforting them. It also happens that the nurses on duty are all very junior, have not seen a death before, and have not performed the last offices. The sister has to take one of these nurses to help her deal with the dead person. Anyone experienced in hospital work will know the characteristic atmosphere which descends on a ward when a death takes place. Many of the patients will have been friends of the dead person and they begin to wonder about their own position. Regression is not an uncommon reaction to illness. In a state of regression people become more demanding; they demand more of the sister's time. To add to existing problems the mortuary porter arrives before the last offices are completed, the pharmacy porter wants sister to sign for the drugs, the medical social worker wants to know if it is convenient to interview a patient she has been requested to see. And an electrician wants to know which socket is out of order.

If we take management in an organisation such as hospital to be a matter of people and human relations involving the use of resources, the case study above provides all the necessary elements.

It is not enough to create a case for a management function; attention needs to be paid to the quality of the management as well. The remaining elements in the functional approach to management, controlling and co-ordinating, take this aspect into account.

Controlling is concerned with the evaluation of performance and can be considered in three stages. These are establishing standards, comparing actual results against the standards, and taking corrective action.

Co-ordinating is the remaining element of functional management. Successful co-ordination of activities results from carrying out effectively the functions of planning, organising, directing, and controlling; it is the synthesis of the various elements in the management process so that the result is a coherent, integrated, and unitary whole.

The nature of nursing, the demands of sound practice, and, more recently, research findings, all point to the conclusion that, whatever else she must be or may be, the ward sister is a manager.

\section{Nursing}

When it comes to the nature of nursing Henderson (1966) is a respected author who has written much on the subject. her concept is that: "The unique function of the nurse is to assist the individual, sick or well, in the performance of those activities contributing to the health or its recovery (or peaceful death) that he would perform unaided if he had the necessary strength, will, or knowledge. And to do this in such a way as to help him gain independence as rapidly as possible.' She goes on to identify a number of specific elements as follows. "The nurse is:

1. the consciousness for the unconscious;

2. the love of life for the suicidal;

3. the leg of the amputee;

4. the eyes of the newly blind;

5. the means of locomotion for the infant;

6. knowledge and confidence for the young mother:

7. the mouthpiece for those too weak or withdrawn speak."
It has been said, and perhaps rightly, that nursing is concerned with care rather than cure. And a fundamental element in the caring process is compassion. This includes a feeling for the subject of care as well as practical help and assistance. Does the ward sister show compassion? One can postulate that this was so in the case study cited; the sister would not only feel sympathy for the bereaved but would also provide practical help.

Caring involves trust, tact, confidence, and hope. We can expect the ward sister to create trust between her and her patients and to be tactful in her caring role; we can expect a state of confidence to exist between her and her clients; and we can expect her to have a hopeful outlook. Since a role consists of the function of the individual who assumes it, we can say that nursing includes a caring role.

Let us move on to skills. We find that there are two types of skills in the practice of nursing. The first of these is skill in human relations and the second involves manual dexterity. From the work of Lelean, cited earlier, we saw that a sister spends much time communicating with nurses and other personnel. However it was found that "the meaning of the sister's instructions could not be interpreted with reliability."

"The instruction 'up and about' had eight different meanings" and it was found that a particular instruction could have up to three different meanings on the same ward on the same day. But if we accept nursing is an emerging profession then this state of affairs, while not acceptable, is more understandable.

In the case of physical skills the Royal College of Nursing reports also have something to offer. Referring back to the first of the specific points put forward by Henderson, "the nurse is the consciousness of the unconscious", we might wish to argue that since the ward sister is probably the best qualified nurse in a ward, certainly the most senior, then caring for the unconscious ought to be part of her job. But Jones, already cited ( $p 76$ ), found that, for example, when it comes to preparing feeds for unconscious patients the ward sister exercised this skill very infrequently. It was found that learners, pupil and student nurses, prepared the feeds 88 per cent of the time while the sister prepared them only 0.7 per cent of the time.

\section{The nursing process}

There is an alternative way of looking at nursing and this is through the nursing process. The concept of process embodies three essential elements; purpose, organisation, and innovation. Purpose and objectives, though not synonymous terms, are closely related. The second characteristic is organisation, and as far as the nursing process is concerned, this has four aspects.

1. assessment, which is identification of the patient's needs;

2. planning, which is establishing priorities by deciding which problems are the most urgent;

3. implementation, which is the actual giving of nursing care;

4. evaluation, which is a feedback mechanism and designed to improve the nursing standards; 
If we refer again to the case study cited earlier and relate the elements of the nursing process to the functions of the ward sister, it may be pcssible to establish whether or not she is a nurse. Does the ward sister concentrate her attentions on the relatives of the dead person; on the other patients who are now making unreasonable demands on her scarce time; or on the various visitors to the ward; or on the young nurse who has come across death for the first time and is frightened by it? Clearly, since she cannot be everywhere at once she will have to make assessments and establish priorities. She will, therefore, be active in two areas of the nursing process; in other words she will be nursing.

As far as implementation goes she will be communicating her order of priorities to those concerned and since communication and skill in human relations are nursing functions, the sister will be nursing when she does this. With regard to evaluation, we have already made a case for a management element in the ward sister's role. Now controlling is an essential part of the management process and is concerned with the evaluation of performance. This evaluation is concerned with standards of nursing care, and, where necessary, taking corrective action. A ward sister in common with any professional, will be keeping a weather eye on the standards of practice.

The ward sister may be involved in innovation in two ways. She may be an innovator in her own right constantly modifying and adjusting her practices in the light of her own experiences. Secondly, she may follow the innovating leads given by others as reported in the journals.

Significant innovatory changes have taken place on a widespread scale over the past decade. One of these concerns the time patients are called in the morning. The tendency is to call patients later than was previously the case. Another shift has taken place in the case of visiting times which are generally more flexible than previously, particularly in the case of children. There has been a shift, too, towards earlier ambulation. In the case of specific nursing procedures, there has been change, for instance, in dealing with pressure areas. At one time the use of spirit was commonplace; now it is rarely, if ever, used.

It seems to follow that if we relate the role of the ward sister to the nursing process model of nursing we can link her functions to all parts of the process. We can therefore ascribe a nursing function to the role of the ward sister.

\section{Teaching}

Of the three elements in the title of the essay, only teaching remains to be considered. The first question that then springs to mind is what is teaching? According to the Shorter Oxford Dictionary teaching is: "The imparting of instruction; the occupation or function of a teacher, that which is taught; a thing taught, doctrine, instruction, precept." The dictionary definition is all right as far as it goes; but since teaching is a process, we need to consider what progression takes place in order to establish a truer concept of what teaching is about.

Let us examine the proposition that teaching consists of stimulating people to attend, to observe, to associate, to remember, and to reason. One way of getting this proposition to stand is to show its relationship with concepts already accepted.

Educationists, too, have been much concerned with objectives. Two important works on the subject are by Bloom (1956) and Krathwohl (1964), but it is the second of these that we will turn to for support for the proposition about teaching set out above.

Krathwohl's book as its title suggests, Taxonomy of Educational Objectives; Affective Domain, is concerned about the feeling aspect of learning. The first major category which he describes in the affective domain is receiving. According to Krathwohl receiving refers to the student's willingness to attend to particular stimuli. From a teaching viewpoint, it is concerned with getting, holding, and directing the students' attention. Learning outcomes in this area range from the simple awareness that a thing exists to selective attention on the part of the learner. Receiving, therefore, represents the lowest level of response in the affective domain. Krathwohl goes on to give examples of general and specific objectives. A general objective would be that the student listens attentively and the verbs used for specific objectives include words such as asks, chooses, describes, identifies, locates, names and replies.

To say that willingness to attend is necessary for learning to take place may appear like a case of stating the obvious; yet if a student does not attend, how can learning take place? There seems to be every reason for accepting the proposition that teaching consists of stimulating others to attend.

We can see, though formal training in methods of teaching may be advantageous, that any person has the potential capacity to engage another person's attention. The ward sister, because of the status normally attributed to persons occupying that role, has an obvious lead in this respect. Her status and her professional knowledge put her in a good position not only to stimulate her learners to attend but also to enable them to observe what is essential; to associate the normal and the abnormal and so form generalisations and to formulate concepts and principles; to remember the important points; and to reason about what may be happening.

Another important aspect of the ward sister's work is the teaching of patients. In a health education context teaching can be seen as a process which enables a patient to learn to use his potential for health and happiness. But sometimes sights may need to be lowered. If we go back to Henderson's point that a nurse is "the leg of the amputee" we can see that a patient who has lost a limb has to make considerable adaptation. The ward sister in her role as a health educator can help in this process of adaptation.

\section{Teaching patients}

One example is not enough to establish a patient teaching role for the ward sister. But there are many more to draw upon. In practising midwifery, both in the pre- and postnatal periods, teaching about motherhood and mothercraft is an integral element of the ward sister's job. In community nursing there are opportunities both to help in the process of adapting the 
limitations imposed by illness and for more positive health education. The person with pernicious anacmia needs to be taught how to manage this condition; so do persons with diabetes, epilepsy, a gastric ulcer, and so does someone who has had a coronary thrombosis. But people with either ileostomies or colostomies are a special case in point. Good teaching is essential if people are to adapt to these conditions so that they can lead lives which are as full as possible.

From what has been said, the purpose of teaching seems to be to enable learning to take place. This leads us on to ask if a teacher and learner relationship is always necessary for learning to take place. The answer, of course, is no. There is also the concept of socialisation and social learning; but what do these terms mean? McDavid and Harari (1974) define them as follows: "The term socialisation refers to the sequence of social learning experiences that result in the integration of the individual into a society. One might describe and analyse the socialisation process with respect to an individual's assimilation into a particular group.",

The concept of socialisation also takes account of what are called significant others in environment. The process of becoming a nurse involves socialisation so that at the end of the process the person will be accepted into the ranks of professional nurses. The ward sister, even if she made no attempt to stimulate the nurse to attend, observe, associate, reason, or remember, would be a significant person in the nurse's environment and as such would be likely to have exerted an influence.

McDavid and Harari go on to say: "The key to socialisation is social learning. Psychology defines learning as any modification of behaviour resulting from experience in the environment ... The kind of learning with which social psychology is particularly concerned is any learning that occurs with social elements in the environment; other people, groups, or cultural products and institutions.",

\section{Modelling}

Danziger (1976) deals with another aspect of socialisation, namely modelling. According to this author the key to modelling is observation because he says: "It is observation of the model and not interaction with the model that is necessary for social learning to take place." This is in keeping with the point made above that while a ward sister may make no attempt whatever to teach, the fact that she is a significant person in the environment means that in the role of a model she may cause social learning to take place.

It is necessary to say may cause, for Danziger goes on to say that "the source of power of models which are considered worth imitating is elusive. At this stage it may help to make a distinction between two kinds of models, personal models and positional models. A personal model is followed for the sake of his personal attributes, a positional model for the sake of the attributes that pertain to his social position as defined by sex, age, occupation".

The ward sister may or may not be seen to be worth imitating as a personal model because of the elusive nature of the reasons why models are chosen. But she is on much stronger ground as a positional model because of the status associated with her job. It is in that capacity that her example is most likely to be imitated.

\section{Conclusion}

This analysis of the role of the ward sister has demonstrated two things. The first is the diverse nature of the demands which are made on ward sisters. By the use of a case study approach it has been possible to demonstrate that the ward sister is involved in planning, organising, communicating, directing, controlling, and co-ordinating. Since these are the principal elements found in functional management, it may be concluded that the ward sister's role includes an element of management.

Using the nursing process model of nursing it has been possible to demonstrate that the ward sister is involved in assessing, planning, implementing, and evaluating. Since these are the principal elements of the nursing process it may be concluded that the ward sister's role includes an element of nursing.

The position of teaching is somewhat different. The opportunities for teaching in the sense of imparting knowledge to learners and patients exist and may or may not be taken up. When the pressures from other sources are great, it is teaching that is likely to fall by the wayside. Imparting knowledge, however, is only one part of the story. There is also social learning. In this case the ward sister may act as a role model for both learners and patients without any conscious effort on her part. Her presence is all that is required.

The second point to emerge is that while management, nursing, and teaching have their separate and distinctive approaches to the study of people and processes, they do share common ground. A major example of a shared concept concerns objectives. Management is concerned with objectives. So is the nursing process model of nursing. And the practice of teaching is increasingly concerned with the use of objectives.

Having identified that the role of the ward sister includes elements of management, nursing, and teaching, what next? One important implication concerns the preparation for the role of ward sister. It follows that it should include training in management and teaching and should be designed to up-date nursing knowledge and practices. The preparation should take account of social learning and the process of socialisation as well.

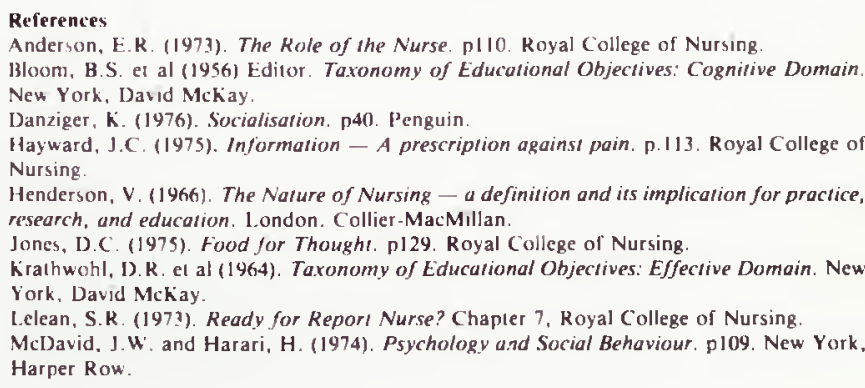

Ihis is an abridged version of the essay which was awarded second place in the Baillière Prize for Nursing Studies, 1977. 